\title{
Job Satisfaction and Prevalence of Stress Signs
}

\author{
Mai Sabry Saleh, Eman Eltahlawy, Nagat Amer \\ Environmental and Occupational Medicine Department, National Research Centre, Dokki, Giza, \\ Egypt
}

\begin{abstract}
Exposure to environmental stressors exert debilitating effects on the health of employees. Workforce in Egypt does not receive -in most cases- suitable preventive measures to face such a problem. Moreover, they lack the awareness of early signs and symptoms of stress. The aim of the present work was to investigate the interrelationship between work stress in terms of physiological and psychological signs and job satisfaction among the Training and capabilities Development Unit (TCD) in National Research Centre of Egypt (NRC). Some personality traits and learning styles were also investigated as predictors of stress. Forty two (12 males and 30 females) employees working at the different departments of TDC were recruited in the study. The sample subjects were asked to complete a survey to estimate their job satisfaction and another for work stress assessment. Participants were asked to fill the Intellectual Style Inventory (ISI) for learning style assessment in addition to some other personality traits. Participants reached 70\%. Significant positive association was detected between low job satisfaction and high score on the work stress scale. The judging personality, the front left thinking, the base left perception and the front right thinking styles showed significantly to be the least suffering from signs of stress. Low job satisfaction is associated with work stress prevalence and helps in increasing psychological and physiological signs of distress. The different learning styles as described by the ISI show different responses to work stress and could be beneficial in similar studies.
\end{abstract}

Keywords: workplace stress, environmental stressors, stress signs, Intellectual Style Inventory, job satisfaction

\section{INTRODUCTION}

Occupational stress or work related stress attribute to how persons are drained by mental and physical pressures at work to the extent that they may fail to achieve their career goals (Kolakar, 2002). Physiological and psychological stress are the two dimensions of occupational distress. The former represents the physiological reaction of the body to stressors like headache, abdominal pain, chest pain, fatigue, sleep disturbance and heart palpitation in addition to changes in eating, sleeping and smoking habits (Critchley et al., 2004). While the later (psychological stress) represents the emotional reaction of an individual to stressful stimuli which include anxiety, depression, tension, anger, nervousness, frustration, irritability and others (World Health Organization, 2005).

The WHO (World Health Organization) emphasizes in the Protecting Workers Health Series No. 6 (2006) that persistence of stress without management could exert various negative effects on both workers and the companies they work for. Effects on workers may include physiological health (musculoskeletal, cardiovascular...), psychological health (anxiety, depression), as well as the worker's cognition and behaviors. Despite stress does not represent a health impairment in itself, yet, stress is the first sign alarming for such harmful physical and emotional consequences (International Labor Organization, 2016).

Job-Satisfaction is a measure that indicates how people feel about the nature of the job tasks, as well as aspects of the work situation that are external to the job tasks (Hirschfeld, 2000). Job satisfaction is sought to be an indicative predictor of performance (Lise et al., 2004). Moreover, many scholars believe that physiological stress, psychological stress, and job satisfaction although distinct, yet, represent highly interrelated constructs (Ismail et al., 2009). A close relationship is also encountered between work stress, Job-Satisfaction and deteriorated health outcomes (Khamisa et al., 2016)

Extensive research also targets the relation between personality traits and preferred learning styles of individuals and their degree of susceptibility and response to job stress, job satisfaction and job performance (Duff et al., 2004; Zhang, 2003; Hurtz and Donovan, 2000). 
According to the WHO (2007), occupational stress is a matter of growing concern in developing countries. Nevertheless, little is known about stress incidence in such countries. Moreover, almost no information describing the prevalence of work-related stress and its psychosocial risks in Africa and the Arab States are ever available (International Labor Organization, 2016). As for Egypt, some sporadic trials that could be considered as pilot studies had been carried out and could give us some estimates of the general condition regarding work stress and its prevalence in the working environment. One of these studies is the cross sectional study carried out by Shams and El-Masry (2013), which showed that $69.4 \%$ of 98 anaesthesiologists working at Mansoura University Hospital in Egypt were encountering job stress. Another study was held among 200 employees working in a multinational Oil and Gas company in Egypt and emphasized the presence of a strong causal relationship between certain work factors and occurrence of work related stress (Ghobrial et al., 2016).

The present study is a cross-sectional explorative study that investigates the interrelationship between work stress in terms of physiological and psychological signs, personality traits, learning styles and job satisfaction. The study is performed upon a pilot sample of adult employees in the Egyptian working environment.

\section{Methodology}

Egyptian employees working at different departments of the Training and Capabilities Development Unit (TDC) of the National research centre (NRC) of Egypt were recruited in the study. The sample subjects were asked to complete a questionnaire which included indirect measure (Ho et al., 2009) of job satisfaction through a single screening question (Do you find your job boring?) with an expected answer of yes or no. Participants were also asked to answer a questionnaire made up of eight items to assess work stress. The questionnaire investigated some physiological signs of distress which are headache, fatigue, laziness and excessive caffeine intake. Irritability, loss of sense of humor, feeling that time moves slowly and loss of concentration represent the psychological signs. Positive answers were given the score one and negative answers were given the score zero. Final score in the work stress scale was a number ranging from zero for those free from any stress signs to 8 for those suffering from all signs under study.

Personality traits (Introversion/Extraversion (I/E) and Judging/Perceiving (J/P)) were measured after adaptation from the Myers Briggs Type Indicator (1975). Besides, the Intellectual Style Inventory (Saleh et al., 2014), was used as a tool for assessment of preferred learning style for all participants using a specialized user friendly software designed for score calculation and graphical representation of results. According to the ISI, each employee has a predominant preference in thinking or the way for taking decisions and a preferential perception style indicating how a person captures data from the environment. The ISI introduces four thinking styles and four perception styles rooted at the four cortical lobes of the brain and is able to detect their order of preference for each individual. Approval was taken from the ethical committee of the NRC for performing the research.

For statistical analysis descriptive tests (frequencies and mean with standard deviation) and comparing means (student t-test and Pearson chi-square) were calculated using the Statistical Package for the Social Sciences (SPSS) 16.0 (SPSS Inc., Chicago, IL, USA).

\section{RESUlts}

Percentage of participation reached $70 \%$ of the total capacity of the TCD (42 out of 60 employees). The sample included 14 males and 28 females with mean age 40.7 years $(\mathrm{SD}=10.2)$ ranging from 22 to 58 years old. Non-satisfied employees who found their work boring represented $14 \%$ of participants while $86 \%$ found their job non-boring. The non-satisfied group showed highly significant $(p=0.000)$ higher score on the work stress scale $(4.0 \pm 2.23)$ compared to the satisfied group (1.4 \pm 1.3$)$, while the whole sample showed mean score of 1.8 with 1.7 as standard deviation.

Frequency distribution and percentages of the different signs investigated by the work stress scale are illustrated in table 1. By frequency, fatigue (17) showed to be the most frequent sign followed by loss of sense of humor (12), while feeling the time moves slowly and laziness showed the least frequency (5) among the non satisfied. 
Job Satisfaction and Prevalence of Stress Signs

Table1. Frequency distribution of physiological and psychological signs of stress

\begin{tabular}{|lc|c|}
\hline \multicolumn{1}{|c|}{ Item } & Frequency (\%) \\
\hline Irritability & Yes & $10(23.8)$ \\
& No & $32(76.2)$ \\
\hline Loss of Concentration & Yes & $6(14.4)$ \\
& No & $36(85.7)$ \\
\hline Headache & Yes & $10(23.8)$ \\
& No & $32(76.2)$ \\
\hline Laziness & Yes & $5(11.9)$ \\
& No & $37(88.1)$ \\
\hline Loss of Sense of Humor & Yes & $12(28.6)$ \\
& No & $30(71.4)$ \\
\hline Fatigue & Yes & $17(40.5)$ \\
& No & $25(59.5)$ \\
\hline Excessive Caffeine intake & Yes & $8(19.0)$ \\
& No & $34(81.0)$ \\
\hline Feeling that time moves slowly & Yes & $5(11.9)$ \\
& No & $37(88.1)$ \\
\hline
\end{tabular}

Table 2. is showing the mean values with standard deviation of the different personality traits and learning styles under study. The personality trait showing the least mean value was the perceiving personality (18.4) and the highest value was recorded for the judging personality (25.6). As for learning styles, the front right cortical lobe showed the least values in both perception (21.3) and thinking (20.7), while the base right thinking style (25.6) and the base left perception style (27.3) showed the highest values.

Table2. Personality traits and learning styles in terms of perception and thinking as mean $\pm S D$

\begin{tabular}{|l|c|c|c|c|}
\hline & Mean & Std. Deviation & Minimum & Maximum \\
\hline Introversion & 22.3 & 3.8 & 14.0 & 30.0 \\
\hline Extraversion & 21.8 & 4.9 & 8.0 & 28.0 \\
\hline Judging & 25.6 & 4.3 & 12.0 & 30.0 \\
\hline Perceiving & 18.4 & 3.4 & 12.0 & 26.0 \\
\hline Front left perception & 24.0 & 3.7 & 14.0 & 30.0 \\
\hline Front right perception & 21.3 & 4.7 & 12.0 & 30.0 \\
\hline Base right perception & 25.1 & 3.6 & 14.0 & 30.0 \\
\hline Base left perception & 27.3 & 3.0 & 14.0 & 30.0 \\
\hline Front left thinking & 24.2 & 3.5 & 14.0 & 30.0 \\
\hline Front right thinking & 20.7 & 4.7 & 10.0 & 30.0 \\
\hline Base right thinking & 25.6 & 3.7 & 10.0 & 30.0 \\
\hline Base left thinking & 24.0 & 2.9 & 18.0 & 30.0 \\
\hline
\end{tabular}

Table 3. is showing the difference between the satisfied and the non satisfied employees in their personalities and preferences in learning styles. The higher score at the judging personality scale (26.2) showed to be significantly $(p<0.05)$ more satisfied with their job than employees with lower score (22.0) at the same scale. Similarly was the case with respect to the base left thinking style at $\mathrm{p}<0.01$, where those with higher means (27.9) were more satisfied with their job. The most prevalent stress signs among the non satisfied group showed to be "loss of concentration' and loss of sense of humor" at $\mathrm{p}<0.01$ and $\mathrm{p}<0.05$, respectively (table 4 ). 
Mai Sabry Saleh et al.

Table3. Comparing means of personality traits and learning styles between satisfied and non-satisfied employees.

\begin{tabular}{|c|c|c|c|c|c|}
\hline \multirow{2}{*}{} & \multicolumn{4}{|c|}{ Do you find your job boring? } & \multirow{2}{*}{ P value } \\
\cline { 2 - 5 } & \multicolumn{2}{|c|}{ Yes } & \multicolumn{2}{c|}{ No } & \multirow{2}{*}{0.011} \\
\cline { 2 - 5 } & Mean & Std. Deviation & Mean & Std. Deviation & 0.76 \\
\hline Introversion & 20.0 & 3.1 & 22.7 & 3.9 & 5.2 \\
\hline Extraversion & 22.3 & 2.3 & 21.7 & 3.6 & $0.026^{*}$ \\
\hline Judging & 22.0 & 6.7 & 26.2 & 3.4 & 0.126 \\
\hline Perceiving & 20.3 & 2.3 & 18.1 & 3.6 & 0.331 \\
\hline Front left perception & 22.7 & 4.1 & 24.3 & 4.6 & 0.979 \\
\hline Front right perception & 21.3 & 5.8 & 21.3 & 3.3 & 0.186 \\
\hline Base right perception & 23.3 & 4.8 & 25.4 & 2.0 & $0.001^{* *}$ \\
\hline Base left perception & 23.7 & 5.0 & 27.9 & 3.2 & 0.168 \\
\hline Front left thinking & 22.3 & 4.6 & 24.5 & 4.4 & 0.855 \\
\hline Front right thinking & 21.0 & 6.9 & 20.6 & 3.7 & 0.661 \\
\hline Base right thinking & 25.0 & 3.7 & 25.7 & 2.9 & 0.768 \\
\hline Base left thinking & 23.7 & 3.2 & 24.1 & & \\
\hline
\end{tabular}

*significant at $p<0.05, * *$ highly significant at $p<0.01$

Table4. Pearson Chi-square for stress signs between satisfied/non-satisfied employees

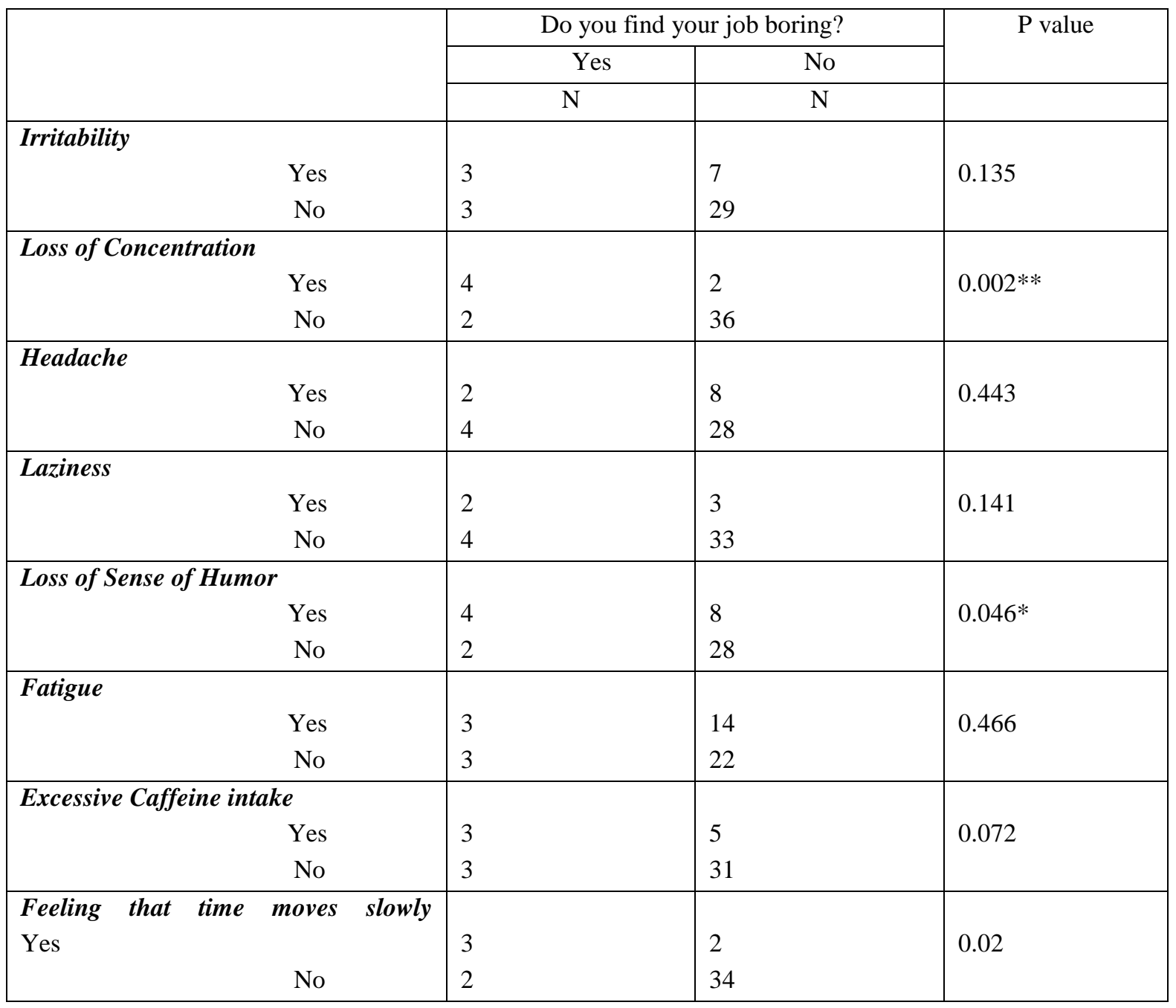

*significant at $p<0.05, * *$ highly significant at $p<0.01$

As shown in table 5. Employees with more score in the front right thinking style showed less prevalence of stress signs at $\mathrm{p}<0.05$. 
Table5. Comparing means of personality traits and learning styles between stressed and non-stressed employees

\begin{tabular}{|c|c|c|c|c|c|}
\hline & \multicolumn{4}{|c|}{ Stress signs questionnaire score } & \multirow[t]{3}{*}{$P$ value } \\
\hline & \multicolumn{2}{|r|}{$<4$} & \multicolumn{2}{|c|}{$\geq 4$} & \\
\hline & Mean & Std. Deviation & Mean & Std. Deviation & \\
\hline Introversion & 22.5 & 3.8 & 21.2 & 4.6 & 0.49 \\
\hline Extraversion & 21.8 & 5.1 & 21.6 & 2.6 & 0.94 \\
\hline Judging & 25.9 & 3.7 & 23.2 & 7.8 & 0.49 \\
\hline Perceiving & 18.2 & 3.4 & 20.0 & 2.4 & 0.26 \\
\hline Front left perception & 24.2 & 3.7 & 22.8 & 3.6 & 0.43 \\
\hline Front right perception & 21.4 & 4.7 & 20.4 & 5.2 & 0.66 \\
\hline Base right perception & 25.4 & 3.3 & 23.6 & 5.7 & 0.31 \\
\hline Base left perception & 27.8 & 2.0 & 23.6 & 5.9 & 0.18 \\
\hline Front left thinking & 24.5 & 3.2 & 22.0 & 5.1 & 0.14 \\
\hline Front right thinking & 21.3 & 4.4 & 16.4 & 5.2 & $0.03 *$ \\
\hline Base right thinking & 25.7 & 3.7 & 24.8 & 3.6 & 0.60 \\
\hline Base left thinking & 24.1 & 2.9 & 23.2 & 3.3 & 0.52 \\
\hline
\end{tabular}

*significant at $p<0.05, * *$ highly significant at $p<0.01$

"The psychological stress signs that showed to be significantly different according to personality trait and learning style preferences were "feeling that time moves slowly" and "loss of concentration". The judging personality and the front left thinking style showed significant lower mean values at the former with $\mathrm{p}<0.01$ and $\mathrm{p}<0.05$, respectively (table 6). While the significantly lower score in the front left thinking style showed to suffer more from loss of concentration. As for the physiological stress signs, table 7 shows that the judging personality and the front left perception styles are the least to suffer from laziness significantly."

Table6. Testing association between psychological signs of stress and personality traits and learning styles

\begin{tabular}{|l|c|c|c|c|c|c|c|c|}
\hline & \multicolumn{3}{|c}{ Irritability } & \multicolumn{2}{c|}{$\begin{array}{c}\text { Loss of sense of } \\
\text { humor }\end{array}$} & \multicolumn{2}{c|}{$\begin{array}{c}\text { Loss of } \\
\text { concentration }\end{array}$} & \multicolumn{2}{c|}{$\begin{array}{c}\text { Feeling that time } \\
\text { moves slowly }\end{array}$} \\
\hline & Yes & No & Yes & No & Yes & No & Yes & No \\
\hline Introversion & $21 \pm 4.1$ & $23 \pm 3.7$ & $23 \pm 3.9$ & $22 \pm 3.9$ & $20 \pm 3.1$ & $23 \pm 3.9$ & $22 \pm 4.2$ & $22 \pm 3.9$ \\
\hline Extraversion & $23 \pm 3.2$ & $21 \pm 5.3$ & $21 \pm 4.0$ & $22 \pm 5.2$ & $23 \pm 3.7$ & $22 \pm 5.1$ & $21 \pm 1.8$ & $22 \pm 5.1$ \\
\hline Judging & $26 \pm 6.3$ & $26 \pm 3.6$ & $26 \pm 5.7$ & $25 \pm 3.7$ & $23 \pm 7.3$ & $26 \pm 3.6$ & $\mathbf{2 0 \pm 6 . 1 * *}$ & $\mathbf{2 6} \pm 3.6^{* *}$ \\
\hline Perceiving & $19 \pm 2.5$ & $18 \pm 3.6$ & $19 \pm 3.4$ & $18 \pm 3.4$ & $20 \pm 3.3$ & $18 \pm 3.3$ & $21 \pm 1.8$ & $18 \pm 3.4$ \\
\hline Front left thinking & $22 \pm 4.4$ & $25 \pm 3.0$ & $25 \pm 4.5$ & $24 \pm 3.1$ & $\mathbf{2 1 \pm 4 . 5 *}$ & $\mathbf{2 5 \pm 3 . 1 *}$ & $\mathbf{2 1 \pm 4 . 4 *}$ & $\mathbf{2 5} \pm \mathbf{3 . 2} *$ \\
\hline Front right thinking & $21 \pm 4.9$ & $21 \pm 4.8$ & $20 \pm 6.0$ & $21 \pm 4.2$ & $18 \pm 4.3$ & $21 \pm 4.7$ & $18 \pm 6.7$ & $21 \pm 4.4$ \\
\hline Base right thinking & $27 \pm 2.9$ & $25 \pm 3.9$ & $24 \pm 5.1$ & $26 \pm 2.8$ & $25 \pm 3.7$ & $26 \pm 3.7$ & $27 \pm 3.9$ & $25 \pm 3.7$ \\
\hline Base left thinking & $24 \pm 2.0$ & $24 \pm 3.2$ & 24.2 .9 & $24 \pm 3.0$ & $22 \pm 1.8$ & $24 \pm 3.0$ & $25 \pm 2.7$ & $24 \pm 3.0$ \\
\hline Front left perception & $25 \pm 4.3$ & $24 \pm 3.5$ & $25 \pm 4.8$ & $24 \pm 3.2$ & $24 \pm 4.3$ & $24 \pm 3.8$ & $22 \pm 3.0$ & $24 \pm 3.8$ \\
\hline Front right perception & $20 \pm 4.6$ & $22 \pm 4.8$ & $21 \pm 4.5$ & $21 \pm 4.9$ & $21 \pm 5.3$ & $21 \pm 4.7$ & $24 \pm 6.0$ & $21 \pm 4.5$ \\
\hline Base right perception & $25 \pm 3.9$ & $25 \pm 3.6$ & $25 \pm 4.0$ & $25 \pm 3.5$ & $23 \pm 5.2$ & $25 \pm 3.3$ & $24 \pm 5.0$ & $25 \pm 3.4$ \\
\hline Base left perception & $26 \pm 5.0$ & $28 \pm 2.0$ & $27 \pm 4.5$ & $28 \pm 2.1$ & $24 \pm 5.4$ & $28 \pm 2.0$ & $25 \pm 6.7$ & $28 \pm 2.0$ \\
\hline
\end{tabular}

*significant at $p<0.05, * *$ highly significant at $p<0.01$

Table7. Testing association between physiological signs of stress and personality traits and learning styles

\begin{tabular}{|l|r|r|r|r|r|r|r|r|}
\hline & \multicolumn{2}{l}{ Laziness } & \multicolumn{2}{l|}{ Fatigue } & & \multicolumn{3}{l|}{$\begin{array}{l}\text { Headache } \\
\text { intake }\end{array}$} \\
\hline & Yes & No & Yes & No & Yes & No & Yes & No \\
\hline Introversion & $23 \pm 3.9$ & $22 \pm 3.9$ & $22 \pm 4.7$ & $22 \pm 3.3$ & $23 \pm 4.6$ & $22 \pm 3.6$ & $23 \pm 4.4$ & $22 \pm 3.7$ \\
\hline Extraversion & $19 \pm 6.4$ & $22 \pm 4.6$ & $21 \pm 5.1$ & $22 \pm 4.8$ & $20 \pm 5.8$ & $22 \pm 4.5$ & $22 \pm 6.5$ & $22 \pm 4.5$ \\
\hline Judging & $\mathbf{1 9 \pm 4 . 6 * *}$ & $\mathbf{2 6} \pm \mathbf{3 . 5} * *$ & $26 \pm 5.2$ & $25 \pm 3.6$ & $26 \pm 5.7$ & $25 \pm 3.9$ & $23 \pm 4.1$ & $26 \pm 4.2$ \\
\hline Perceiving & $20 \pm 3.0$ & $18 \pm 3.3$ & $18 \pm 2.8$ & $18 \pm 3.7$ & $19 \pm 3.9$ & $18 \pm 3.2$ & $20 \pm 3.0$ & $18 \pm 3.4$ \\
\hline Front left thinking & $22 \pm 6.2$ & $25 \pm 3.0$ & $24 \pm 4.1$ & $25 \pm 3.0$ & $24 \pm 4.6$ & $24 \pm 3.1$ & $24 \pm 3.4$ & $24 \pm 3.6$ \\
\hline Front right thinking & $18 \pm 6.7$ & $21 \pm 4.4$ & $20 \pm 5.3 .0$ & $21 \pm 4.4$ & $19 \pm 5.3$ & $21 \pm 4.5$ & $21 \pm 6.6$ & $21 \pm 4.3$ \\
\hline Base right thinking & $22 \pm 7.9$ & $26 \pm 2.4$ & $26 \pm 3.0$ & $25 \pm 4.1$ & $24 \pm 2.9$ & $26 \pm 3.8$ & $27 \pm 3.0$ & $25 \pm 3.8$ \\
\hline Base left thinking & $23 \pm 3.0$ & $24 \pm 3.0$ & $24 \pm 2.2$ & $24 \pm 3.4$ & $23 \pm 2.7$ & $24 \pm 2.9$ & $24 \pm 3.0$ & $24 \pm 3.0$ \\
\hline Front left perception & $\mathbf{2 0} \pm \mathbf{2 . 6 *}$ & $\mathbf{2 5} \pm \mathbf{3 . 6} *$ & $24 \pm 4.2$ & $24 \pm 3.4$ & $24 \pm 3.4$ & $24 \pm 3.2$ & $22 \pm 4.5$ & $24 \pm 3.4$ \\
\hline Front right perception & $20 \pm 5.2$ & $22 \pm 4.7$ & $20 \pm 5.0$ & $22 \pm 4.5$ & $24 \pm 4.2$ & $26 \pm 3.4$ & $21 \pm 4.5$ & $21 \pm 4.8$ \\
\hline Base right perception & $24 \pm 5.1$ & $25 \pm 3.4$ & $24 \pm 4.4$ & $26 \pm 2.8$ & $24 \pm 4.2$ & $26 \pm 3.4$ & $26 \pm 3.5$ & $25 \pm 3.6$ \\
\hline Base left perception & $23 \pm 5.2$ & $28 \pm 1.9$ & $27 \pm 4.0$ & $27 \pm 2.0$ & $26 \pm 4.8$ & $28 \pm 2.1$ & $27 \pm 2.6$ & $27 \pm 3.0$ \\
\hline
\end{tabular}

*significant at $p<0.05, * *$ highly significant at $p<0.01$ 


\section{DISCUSSION}

Very little specific national data on work-related stress is available for developing countries as well as for countries in transition which according to the WHO (2007) could be attributed to poor recording mechanisms. Similarly, among the Arab population, only few reports on clinical stress are available (Amr et al., 2011). These facts represented a trigger to perform the present study and highlighted the urge of putting job stress in developing countries - generally- and Egypt -particularly- under spot.

One of the most important findings of the present study was the highly significant difference $(\mathrm{p}=0.000)$ between the satisfied (4.0) and the non satisfied (1.4) in their scores with respect to work stress scale. According to literature, work related stress contributes to lower job satisfaction (Spector, 1997). Broadly, this could be due to the mismatch between job expectations and the actual working environments (Spector, 1997). Work related factors that are reported to affect job satisfaction include high job demands (Idris, 2011), low professional accomplishment, lack of freedom of expression and absence of appreciation (Maissiat et al., 2015). Factors of influence on job satisfaction also include age, educational background and income (Atif et al., 2015).

Loss of job satisfaction in known to lead to poor health outcomes (Idris, 2011). Prolonged exposure to stressors results in an imbalance in body homeostasis followed by breakdown of the biological system that affects in turns the compensatory and anticipatory changes that aid in coping with work stress (Piko, 2006). In this context, prevalence of both physiological and psychological sign of stress were investigated in the present work represented by headache, fatigue, laziness and excessive caffeine intake for the former and by irritability, loss of sense of humor and loss of concentration, feeling that time moves slowly for the latter (Ismail, 2009). Despite, physiological stress, psychological stress, and job satisfaction could be regarded as distinct but by evidence they proved to be highly interrelated. As reported, better job satisfaction is the result of employees being able to master their physiological and psychological stresses in their working environments and vice versa (Antoniou et al., 2003). Nevertheless, how occupational stress really affects job satisfaction is still a question under investigation and needs more research (Guleryuz et al., 2008).

According to the study results loss of sense of humor and loss of concentrations were the signs significantly manifested by the non satisfied group. Yet it was very interesting to find that some kinds of personal characteristics were able to guard against stress signs. For example, the more stressed group (stress scale $\geq 4$ ) showed significantly lower scores in the front right thinking scale. Laziness appeared to prevail among those with significantly lower scores in the judging personality and the front left perception scales. Moreover, "feeling that time moves slowly" also prevailed among those with significantly lower scores in judging scale in addition to those with lower score on the front left thinking style.

The above findings perfectly agree with the fact that individual characteristics greatly affect how individuals cope with stressors as well as how they perceive their working variables (Wichert, 2002). Individual nature also represent a major determinant of job satisfaction regarding the good match between it and the employment requirements (Myers and Myers, 1995). Extensive research has been done -in this concern- on type A and type B personalities (Wainwright \& Calnan, 2002), the big five invented by Goldberg (1972) and few other personality theories, yet, this study is the first to be done using the ISI for learning style preferences (Saleh et al., 2014). Besides, very few is available concerning the I/E and J/P dichotomies as described by the MBTI like that done by Meeusen et al. (2010) for example.

The judging personality is known to plan carefully for his daily life and never surrender to accidental obstacles. This nature could be the reason the judging is the least to suffer from the different signs of stress. The front right thinking style on the other hand is the type of person that lives in the future, his mind is full with ideas and dreams for tomorrow and hence is not tied to the depressing reality. As for the base left perception learner, he works mechanically regardless of driving forces or expected consequences (Saleh et al., 2014).

Knowing the nature of the different personalities and styles could provide exciting explanations about their responses to work stress scale and their state of job satisfaction. For that reason it is highly recommended to reapply the present study on larger scale and among different working environments. It is also recommended to try to investigate the different work related and psychosocial factors that predict stress in order to have a more clear picture about occupational stress and its risk factors. 


\section{REFERENCES}

Amr, M., El-Gilany, A., El-Moafee, H., Salama, L., \& Jimenez, C. (2011). Stress among Mansoura (Egypt) baccalaureate nursing student. The Pan African Medical Journal. African Field Epidemiology Network

Antoniou, A.S.G., Davidson, M.J., \& Cooper, C.L. (2003). Occupational stress, job satisfaction and health state in male and female junior hospital doctors in Greece. Journal of Managerial Psychology, 18(6), 592-621.

Critchley, H.D., Rotshtein, P., Nagai, Y., O’Doherty, J., Mathias, C.J., \& Dolan, R.J. (2004). Activity in the human brain predicting differential heart rate responses to emotional facial expressions. NeuroImage, 24, 751-762.

Duff A, Boyle E, Dunleavy K, Ferguson J: The relationship between personality, approach to learning and academic performance. Personality and Individual Differences 2004,36:1907-1920.

Ghobrial GB, El-din SA and Shenouda MS. Work-Related Stress among Petroleum Company Employees at their Workplace in Egypt. Med. J. Cairo Univ., Vol. 83, No. 1, March: 187-199, 2015 www.medicaljournalofcairouniversity.net

Guleryuz, K., Guney, S., Aydin, E.M., \& Asan, O. (2008). The mediating effect of job satisfaction between emotional intelligence and organizational commitment of nurses: a questionnaire survey. International Journal of Nursing Studies, 45(11), 1625-1635.

Hirschfeld, R.R. (2000). Validity studies. Does revising the intrinsic and extrinsic subscales of the Minnesota Satisfaction Questionnaire Short Form make a difference? Educational Psychological Measurement, 60(2), 255-270.

Ho P. M., Bryson C. L. and Rumsfeld J. S., "Medication Adherence: Its Importance in Cardiovascular Outcomes," Circulation, Vol. 119, No. 23, 2009, pp. 3028-3035. doi:10.1161/ CIRCULATION AHA.108.768986

Hurtz GM, Donovan JJ: Personality and job performance: The Big Five revisited. J App Psych 2000, 85:869-879.

Idris MK. Over time effects of role stress on psychological strain among Malaysian public university academics. International Journal of Business and Social Science 2011; 2: 154-161.

International Labour Organization 2016. Workplace stress: A collective challenge. ISBN: 978-92-2130641-2 (print) 978-92-2-130642-9 (web pdf)

Ismail A., Yao A. and Yunus N. Relationship Between Occupational Stress and Job Satisfaction:An Empirical Study in Malaysia. The Romanian Economic Journal Year XII, no. 34 (4) 2009.

Khamisa N, Peltzer K, Ilic D, Oldenburg B. Work related stress, burnout, job satisfaction and general health of nurses: A follow-up study. International Journal of Nursing Practice, 2016 (C) 2016 John Wiley \& Sons Australia, Ltd

Kolakar, S.H.,Sanakoo, A., Mirkarime, F., Behnampour, N. (2002). The level of stress among Gorgan University of Medical Sciences hospital operation room's personals and its relation to some related factors. J GorganUniv Med Sci.4(2), 54-59.

Lise M. Saari and Timothy A. Judge. Employee Attitudes and Job Satisfaction. Human Resource Management, Winter 2004, Vol. 43, No. 4, Pp. 395-407. DOI: 10.1002/hrm.20032

Saleh M.S., Monir Z. M., Saad-Hussein A., Moustafa S. M., "Intellectual Style Inventory (ISI): Learning Style Assessment after Cortical Functional Specialization," British Journal of Education, Society and Behavioral Science, Vol. 4 No. 7, 2014, pp.987-1005.

Meeusen VCH, Brown-Mahoney C, van Dam K, van Zundert AAJ, Knape JTA. Personality dimensions and their relationship with job satisfaction amongst dutch nurse anaesthetists.JNurs Manag. 2010;18:573-81.

Myers IB, Myers PB. Gifts differing: understanding personality type. Mountain View, USA: CCP, Inc.; 1995.

Myers, I. B., \& Briggs, K. (1975). The Myers-Briggs type indicator (Form G). Palo Alto, CA: Consulting Psychologists Press.

Piko BF. Burnout, role conflict, job satisfaction and psychosocial health among Hungarian healthcare staff: a questionnaire survey. International Journal of Nursing Studies 2006; 43: 311-318. 
Shams, T. \& El-Masry, R. (2013). Job Stress and Burnout among Academic Career Anaesthesiolog ists at an Egyptian University Hospital. Sultan Qaboos Univ Med J, 13(2): 287-295.

Spector PE. Job Satisfaction: Application, Assessment, Causes and Consequences. London, UK: Sage Publications, 1997.

Wainwright, D., \& Calnan, M. (2002). Work stress: The making of a modern epidemic. Buckingham: Open University Press.

World Health Organization-AIMS Report on Mental Health System in (Egypt), WHO and Ministry of Health, Cairo,Egypt, 2006. http://www.who.int/ occupational_health/ publications/ raising ware nessof stress.pf

Wichert, I. (2002). Job insecurity and work intensification: The effects on health and wellbeing. In B. Burchell, D. Ladipo, \& F. Wilkenson (Eds.) Job insecurity and work intensification (pp. 92111). New York, NY: Routledge.

World Health Organization (2007). Authored by: Houtman I, \& Jettinghoff K. Raising Awareness of Stress at Work in Developing Countries A modern hazard in a traditional working environment (Protecting Workers' Health series No. 6). Geneva: WHO

World Health Organization (WHO) (2005). Mental health and working life. WHO European Ministerial Conference on Mental Health: Facing The Challenges, Building Solutions. Retrieved June 19, 2007, from www.euro.who.int/document/mnh/ebrief06.pdf.

Zhang L-F: Does the big five predict learning approaches? Personality and Individual Differences 2003, 34:1431-1446.

Maissiat GS, Lautert L, Pai DD, et al. Work context, job satisfaction and suffering in primary health care. Revista Gaúcha De Enfermagem 2015;36:42-9.

Atif K, Khan HU, Maqbool S. Job satisfaction among doctors, a multi-faceted subject studied at a tertiary care hospital in Lahore.Pak J Med Sci 2015;31:610-14. 